\title{
Harmonic Analysis of Symmetrical and Asymmetrical Cascaded H-Bridge Multilevel Inverter
}

\author{
${ }^{\text {a }}$ Muhammad Ammar*, a Abdul Sattar Larik, ${ }^{a}$ Mukhtiar Ahmed Mahar, ${ }^{\text {a }}$ Amir Mahmood Soomro, \\ ${ }^{\mathrm{b}}$ Muhammad Maaz Siddiqui, ${ }^{\mathrm{c}}$ Syed Muhammad Sabih Masood \\ a: Department of Electrical Engineering, MUET Jamshoro. \\ b: Department of Electrical, University of Windsor Canada. \\ c: Department of Electrical Engineering, NEDUET Karachi.
}

\begin{abstract}
This paper proposes harmonic comparison between symmetrical and asymmetrical CHB MLI using multiple carrier based phase disposition PWM technique (PDPWM). Topologies of different multilevel inverter are reported in the literature, but mainly this work focuses on the harmonic comparison of symmetrical and asymmetrical cascaded MLI with same count of sources and switches. In this paper, PWM switching technique for harmonic comparison of both symmetrical and asymmetrical cascaded MLI is PD. Total harmonic distortion is analyzed in FFT window. Results are observed in SIMULINK/MATLAB software. In these comparative results we can see that an asymmetrical configuration is producing higher voltage levels in voltage output with equal quantity of component compared with the 5-level symmetric inverter and this could lead towards the reduction in harmonic content of output voltage. The benefits of this method of control are applicability and simplicity for n-levels MLI, with no any considerable change in the control circuitry. The experimental measurement results validate proper operation of the discussed MLI.
\end{abstract}

Keywords- Multilevel Inverter, Cascaded H-Bridge, Phase Disposition, Pulse width Modulation.

Date Received 28-11-2019

Date Accepted 25-12-2019

Date Published 31-12-2019

\section{INTRODUCTION}

$\mathrm{T}$ HE Multilevel inverters have drawn growing interest in latest years, in particular within the distributed electrical resources region, because fuel cells, solar cells, rectified wind turbines and several batteries can be connected via a multilevel inverter to feed a load or interconnected to the $\mathrm{AC}$ grid without voltage balancing issues.

The Cascaded multilevel inverter is one of several multilevel configurations. The idea of this inverter is based on connecting $\mathrm{H}$-bridge inverters in series to get a sinusoidal output voltage. The voltage output is sum of the voltages which are generated by each cell. The switching angles are needed to be selected in such a way that the THD can be minimized. The generated harmonics certainly cause reduction in the power quality of the whole system. Hence, it is equally important to reduce the harmonic injections from these converters.

Efforts are being made to improve the design of inverters in such a way that not only their power consumption is reduced but also their harmonic contents get minimized.

An N-level CHB Multilevel inverters need 2(n-1) switching devices where the number of output voltage levels are $\mathrm{N}$.

For this purpose, many topologies of inverters have been proposed that give a multilevel output which is near to a complete sinusoidal waveform. The power quality of an inverter output is proportional to the number of levels in output waveform.

Based on the choice of direct current voltage sources used, multilevel inverters are classified as;

1. Symmetrical Multilevel Inverters

2. Asymmetrical Multilevel Inverters

In symmetrical MLI, all of the direct current voltage sources have same voltage amplitude and the output of such inverters is simply the addition of voltages of all direct current sources. By this, the counts of direct current source are equal to the desired number of output voltage levels [2].

While in asymmetric multilevel inverters unequal direct current sources are used to provide more flexibility and increased output voltage levels with the same number of DC sources. Hence, increased voltage output levels can be obtained with the same number of direct current sources. This proves to be a more efficient way for generation of voltage levels [2].

\section{METHODOLOGY}

The asymmetrical and symmetrical CHB topologies has been modeled to be compared through literature review of easy understanding for best chosen multilevel inverter. Development of simulation model of proposed symmetric and asymmetric inverters using MATLAB/Simulink software. Analysis and Comparison of Harmonics and THD of Symmetric and Asymmetric multilevel inverters using simulation models. 


\section{SYMMETRICAL CHB MULTILEVEL INVERTER}

The configuration of proposed Symmetrical Cascaded HBridge MLI is shown in Fig. 1. The Basic switching units can be connected in series to increase the number of voltage level appears in the converter output.

while calculation of size of direct current voltage source for a MLI, it must be noted that all of the voltage steps should be generated in the converter output using available voltage sources.

The proposed inverter can have symmetric configuration such that each one of the direct current voltage source has same values. On this condition, with $\mathrm{n}$ number switching units, the number of output voltage steps are equals to

\section{Comparison Between Multilevel Converters}

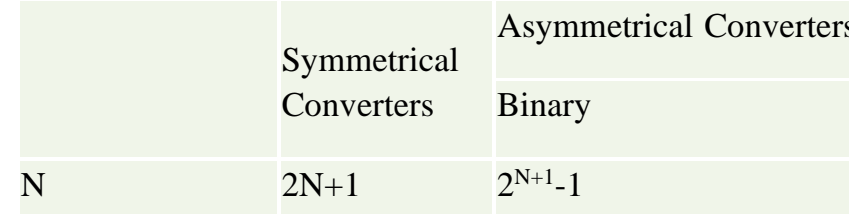

Sources Number

(DC)

$\mathrm{N} \quad \mathrm{N}$

Number Of

Switches

$4 \mathrm{~N}$

$4 \mathrm{~N}$

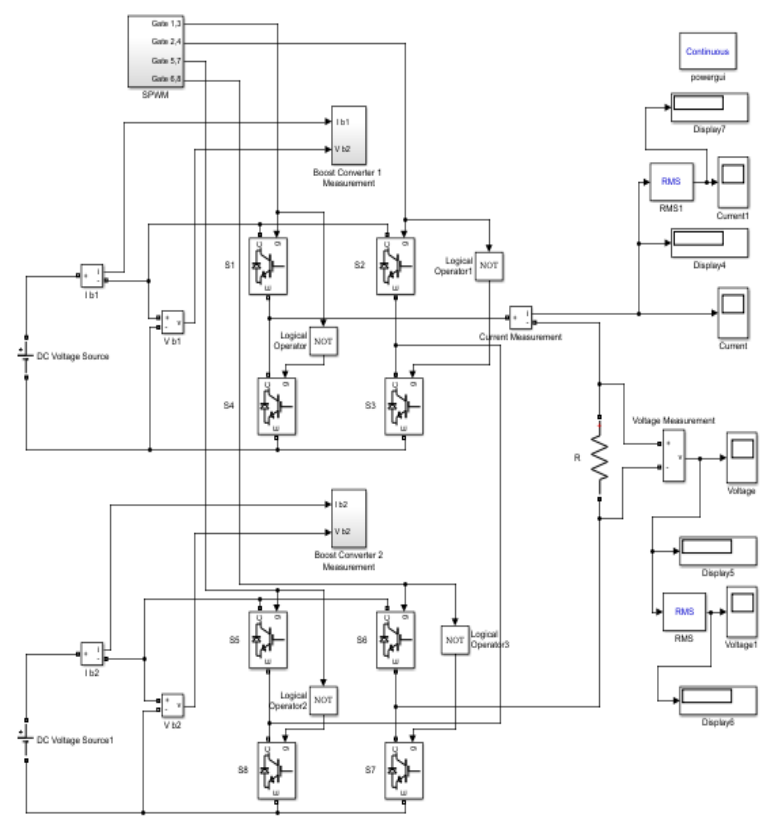

Fig.1

Modeling of Symmetrical Cascaded H-Bridge Multilevel Inverter

Table-I shows switching table of symmetrical CHB MLI with output voltage levels in conventional arrangements as based on different switching states we can get different output voltage levels.

\begin{tabular}{|c|c|c|c|c|c|c|c|c|c|}
\hline \multicolumn{10}{|c|}{ Switching Table Of Symmetrical CHB MLI } \\
\hline Mode & Output Voltage & $S 1$ & $S 2$ & $S 3$ & $S 4$ & $S 5$ & $S 6$ & $S 7$ & $S 8$ \\
\hline 1 & $+2 V d c$ & 1 & 1 & 0 & 0 & 0 & 0 & 1 & 1 \\
\hline 2 & $+V d c$ & 1 & 1 & 0 & 0 & 0 & 0 & 0 & 0 \\
\hline 3 & 0 & 0 & 0 & 0 & 0 & 0 & 0 & 0 & 0 \\
\hline 4 & $-V d c$ & 0 & 0 & 1 & 1 & 0 & 0 & 0 & 0 \\
\hline 5 & $-2 V d c$ & 0 & 0 & 1 & 1 & 1 & 1 & 0 & 0 \\
\hline
\end{tabular}

Table. I. Symmetrical CHB MLI Switching Table

\section{ASYMMETRICAL CHB MULTILEVEL INVERTER}

In symmetrical MLI, all voltage sources have the equal amplitude. That is why the multilevel inverter voltage output is generated by straight adding $\mathrm{V}_{\mathrm{dc}}$ sources. This is an ineffective methodology for selecting and using direct current sources in the multilevel inverter.

From the other side, asymmetrical multilevel inverter configuration is more efficient way to use proper DC sources. When using of unequal direct current sources $\mathrm{V}_{\mathrm{dcn}}$ instead of equal sources in asymmetrical configuration. it will give us more variety by changing different values of $\mathrm{V}_{\mathrm{dc}}$ sources to each other. That is why it generates increased voltage output levels as compared to symmetrical way in similar multilevel inverter configurations. [5]

To select the values of direct current sources $V_{d c n}$ in asymmetric multilevel inverter is a difficult task. Correct values of direct current sources will provide symmetrical and uniformed voltage output levels. Tertiary and binary methods are two common topologies to find out the amplitudes of $\mathrm{V}_{\mathrm{dcn}}$ in asymmetric configurations.

For trinary method, the amplitude of $\mathrm{V}_{\mathrm{dcn}}$ is to be selected as a geometric progression of power ' 3 '. While in binary, the amplitude of $\mathrm{V}_{\mathrm{dcn}}$ is to be chosen as a geometric progression of power ' 2 '.

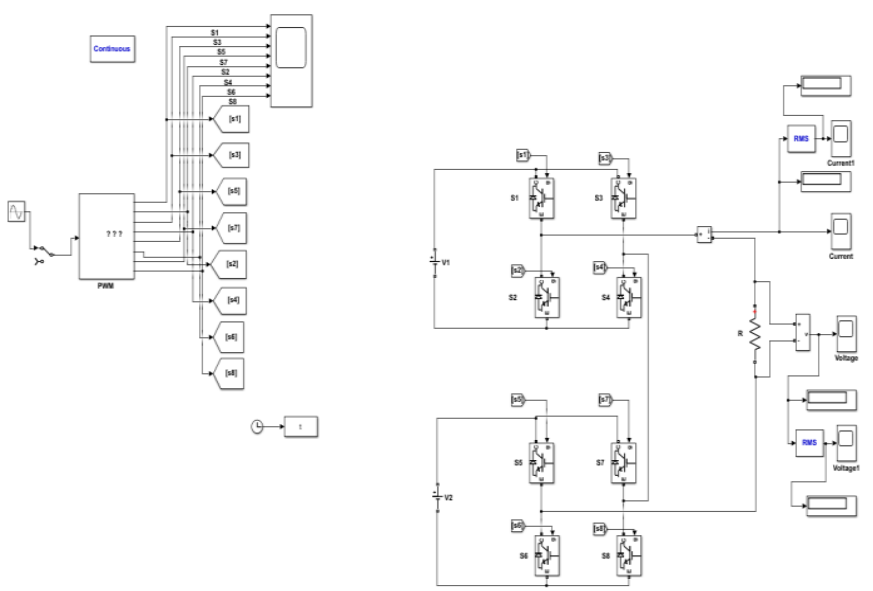

Fig. 2

Modeling of Asymmetrical Cascaded H-Bridge Multilevel Inverter 
Table-II show switching table of asymmetrical CHB MLI with concerned output voltage levels in conventional arrangements as based on different switching states we can get different output voltage levels.

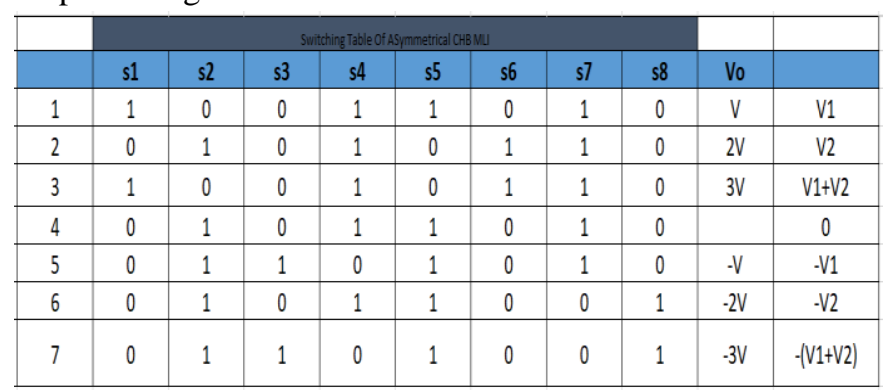

Table. II. Asymmetrical CHB MLI Switching Table

\section{MODULATION TECHNIQUE}

According to the frequencies of switching for multilevel inverters, there are two major groups which can be classified as higher and fundamental switching frequency. [22]. MCPWM method is introduced to achieve an improved quality waveforms of output voltages. Many of the industries implements sinusoidal pulse width modulation technique SPWM for generating switching pulses which is the easiest method. We have used the method in which PWM signals are generated by comparing triangular carrier signals with sinusoidal reference signals. Strategy of phase disposition is applied for the carrier arrangements which have the same frequency, peak to peak amplitude and in phase accordingly. This technique is feasible for reducing the percentage total harmonics distortion(\%THD) and distortion factor (DF).

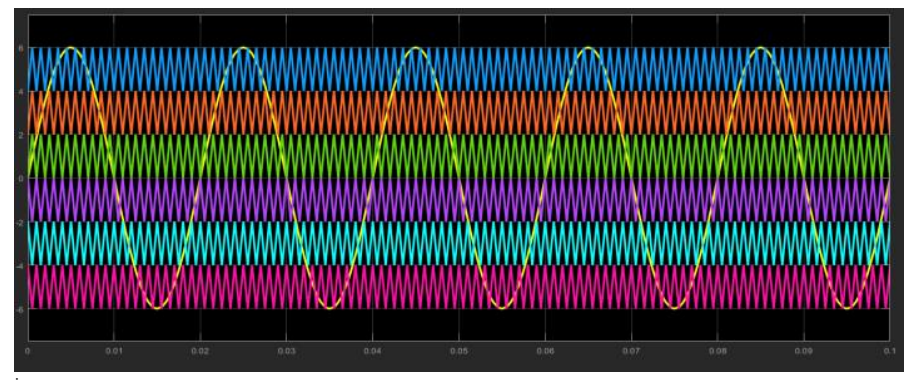

Fig. i3

In Fig. 3 which shows the carrier arrangements of sinusoidal pulse width modulation technique with phase disposition strategy to produce output voltage of Asymmetric sequence CHBMLI. From Fig.3, Six carriers are required for producing 7-levels voltage outputs, in which carriers are equally arranged below and above the point zero reference. The triangular carriers continuously compared with sinusoidal reference signal.

\section{SIMULATION RESULTS}

The CHB asymmetrical and symmetrical MLI are tested with experimental setup and simulation. Both inverters have equal number of DC sources and switches.

In results we can see that with exact same count of direct current sources we are getting higher level of outputs in asymmetrical inverter.

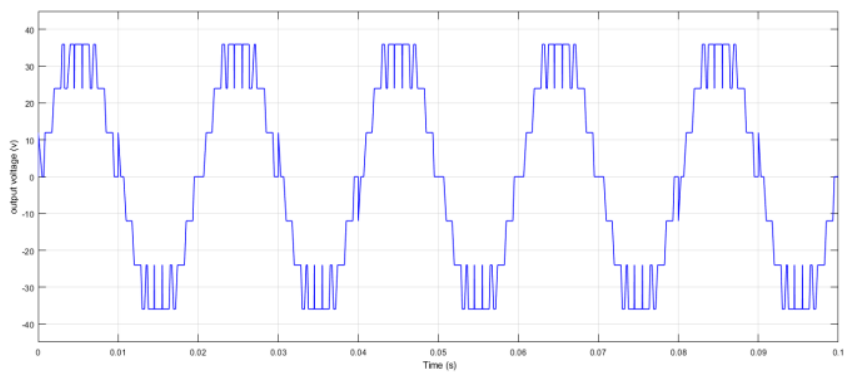

Fig. i4

Output voltage waveform of asymmetrical CHB

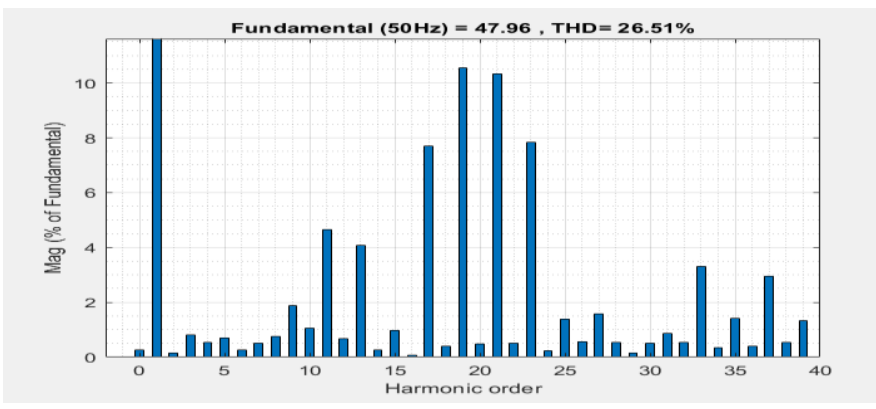

Fig. i5

Harmonic Order of Asymmetrical CHB

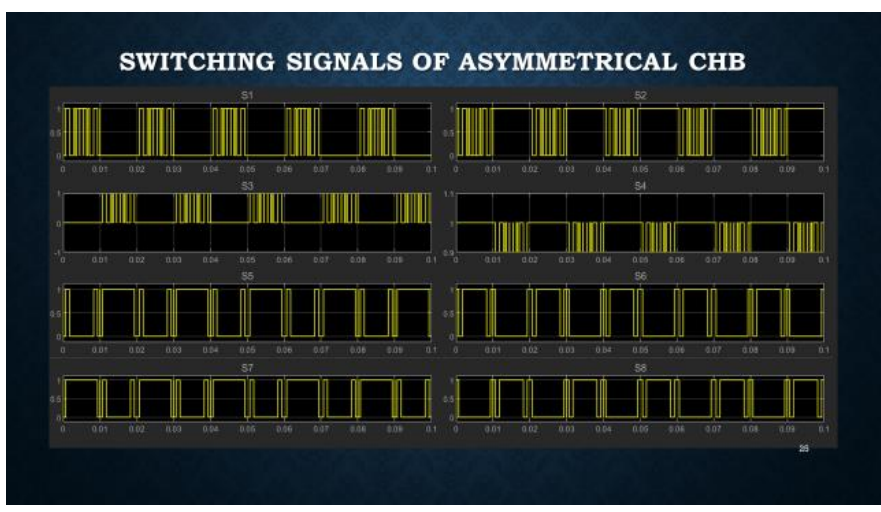

Fig. 6

Switching Signals of Asymmetrical CHB

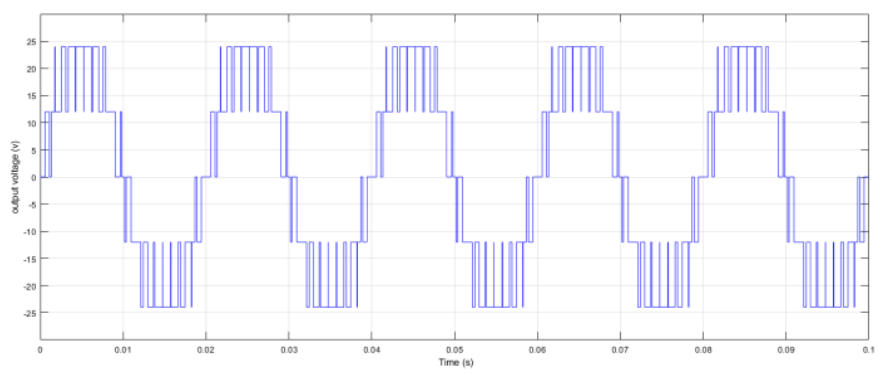

Fig. i7

Output voltage waveform of Symmetrical CHB 


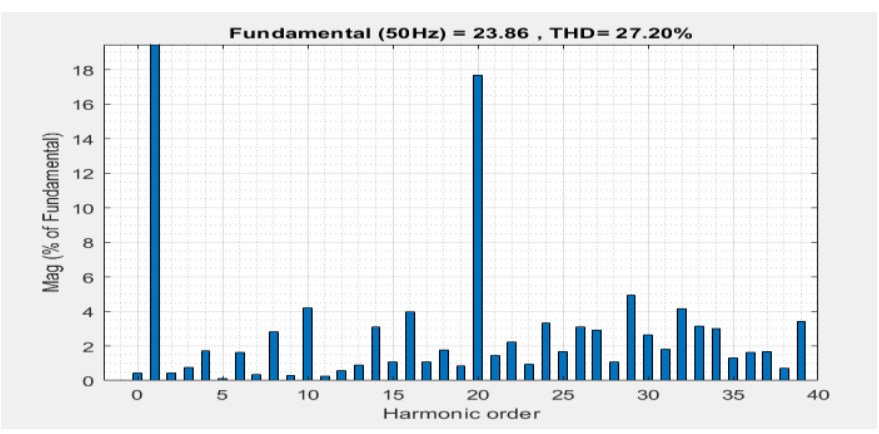

Fig. 8

Harmonic Order of Symmetrical CHB

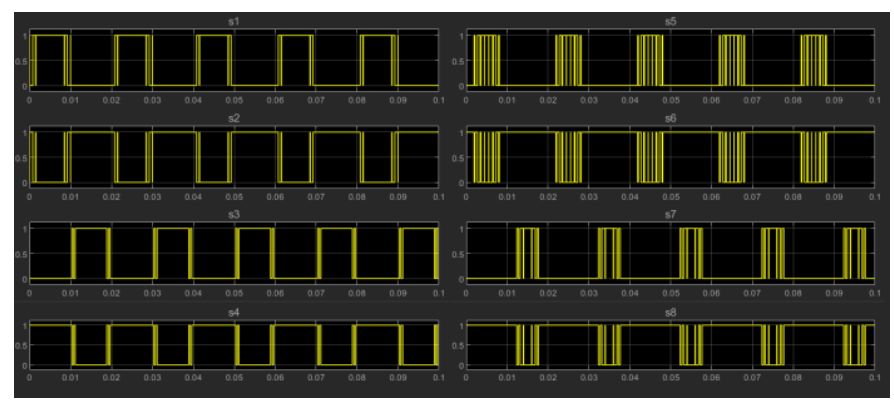

Fig. i9

Switching Signals of Asymmetrical CHB

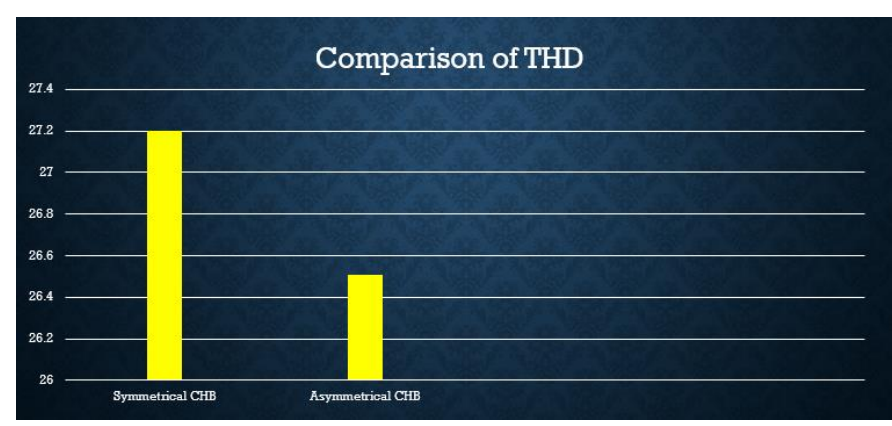

Fig. 10

Comparative THD Results of Both Inverters

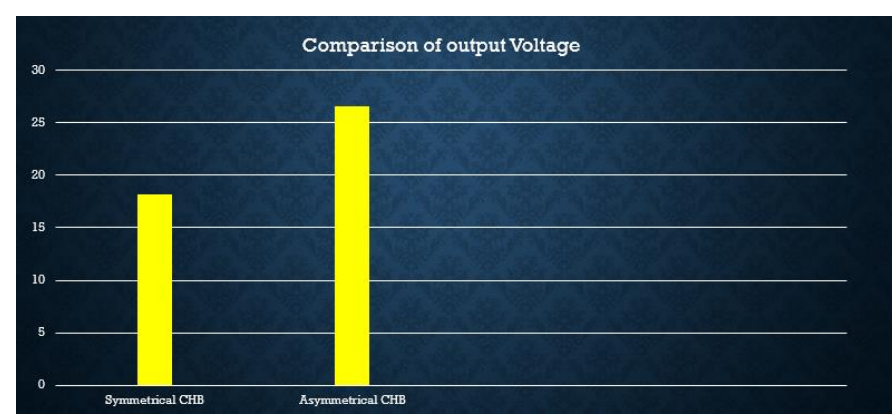

Fig. 11

Comparative Output Voltage Results of Both Inverters

\section{ACKNOWLEDGEMENT}

I would first like to thank my thesis advisors Dr. Abdul Satar and Dr. Mukhtiar Ahmed of the Department of Electrical Engineering at MUET Jamshoro. They always welcomed me warmly and their doors were always open whenever I ran into a trouble spot and had a query about my research work. They always counselled me about this paper to be my own work, and guided me in the right way whenever I needed it.

\section{CONCLUSION}

In this research work, symmetrical and asymmetrical CHB MLIs have been studied.

The simulation models of Symmetrical and Asymmetrical CHB MLI are developed in MATLAB software. The phase disposition MCPWM technique is used to generate the output voltage levels of both converters. The total harmonic distortion in Symmetrical CHB is 27.20 and THD of Asymmetrical is 26.51. From the results, we can be confirming that the Asymmetrical Cascaded H-bridge has less harmonics compared to Symmetrical CHB with same number of switches and sources. Simulation results also show that the Asymmetrical MLI produce more number of voltage output levels as compared to symmetrical cascaded H-bridge multilevel inverter.

\section{REFERENCES}

1. Ozpineci, B., Tolbert, L. M., \& Chiasson, J. N. (2004, June). Harmonic optimization of multilevel converters using genetic algorithms. n 2004 EEE 35th Annual Power Electronics Specialists Conference (IEEE Cat. No. 04CH37551) (Vol. 5, pp. 3911-3916). EEE.

https://ieeexplore.ieee.org/abstract/document/135516 7

2. Jammala, V., Yellasiri, S., \& Panda, A. K. (2018). Development of a new hybrid multilevel nverter using modified carrier SPWM switching strategy. EEE Transactions on Power Electronics, 33(10), 81928197. https://ieeexplore.iee.org/abstract/document/828101 4

3. Nami, Alireza, et al. "Comparison between symmetrical and asymmetrical single phase multilevel nverter with diode-clamped topology." 2008 EEE Power Electronics Specialists Conference. EEE, 2008.

https://ieeexplore.iee.org/abstract/document/459239 3

4. Huang, Jing, and Keith A. Corzine. "Extended operation of flying capacitor multilevel nverters." EEE Transactions on Power Electronics 21.1 (2006): 140-147.

https://ieeexplore.ieee.org/abstract/document/156669 9

5. Ahmed, M., Sheir, A., \& Orabi, M. (2017). Asymmetric cascaded half-bridge multilevel nverter without polarity changer. Alexandria engineering journal https://www.sciencedirect.com/science/article/pii/S11 10016817302612

6. Sedaghati, Farzad, and Naser Hashemipour. "Symmetric Configuration for a Multilevel nverter Using Less Number of Power Switches." nternational 
Journal of ndustrial Electronics, Control and Optimization 1.2 (2018): 91-101.

http://ieco.usb.ac.ir/article_4063.html

7. Babaei, Ebrahim. "A cascade multilevel converter topology with reduced number of switches." EEE Transactions on power electronics 23.6 (2008): 26572664.

https://arxiv.org/abs/1908.10032

8. Ravichandrudu, K., P. Suman Pramod Kumar, and V. E. Sowjanya. "Mitigation of harmonics and power quality mprovement for grid connected wind energy system using UPFC." nternational Journal of Application or nnovation $n$ Engineering \& Management (IJAIEM) 2.10 (2013): 141-156. https://pdfs.semanticscholar.org/57cd/a6dba148901ee 2105b876f30fbc59a42e6a4.pdf

9. Corzine, K. A., Wielebski, M. W., Peng, F. Z., \& Wang, J. (2004). Control of cascaded multilevel nverters. EEE transactions on power electronics, 19(3), 732-738. https://ieeexplore.ieee.org/abstract/document/129674 9

10. Malinowski, M., Gopakumar, K., Rodriguez, J., \& Perez, M. A. (2009). A survey on cascaded multilevel nverters. EEE Transactions on ndustrial electronics, 57(7), 2197-2206

https://ieeexplore.ieee.org/abstract/document/522657 4

11. Prasad, K. N. V., Kumar, G. R., Kiran, T. V., \& Narayana, G. S. (2013, January). Comparison of different topologies of cascaded H-Bridge multilevel nverter. n 2013 nternational Conference on Computer Communication and nformatics (pp. 1-6). EEE https://ieeexplore.ieee.org/abstract/document/646613 5

12. Kumar, P. Roshan, et al. "Seventeen-level nverter formed by cascading flying capacitor and floating capacitor H-bridges." EEE Transactions on Power Electronics 30.7 (2014): 3471-3478. https://ieeexplore.ieee.org/abstract/document/686367 7

13. Rodriguez, J., Lai, J. S., \& Peng, F. Z. (2002). Multilevel nverters: a survey of topologies, controls, and applications. EEE Transactions on ndustrial electronics, 49(4), 724-738.

14. Suresh, Y., Venkataramanaiah, J., Panda, A. K., Dhanamjayulu, C., \& Venugopal, P. (2017). nvestigation on cascade multilevel nverter with symmetric, asymmetric, hybrid and multi-cell configurations. Ain Shams Engineering Journal, 8(2), 263-276.

https://www.sciencedirect.com/science/article/abs/pii /S1364032117303829

15. Chithra, M., \& Dasan, S. B. (2011, March). Analysis of cascaded $\mathrm{H}$ bridge multilevel nverters with photovoltaic arrays. n 2011 nternational Conference on Emerging Trends $n$ Electrical and Computer Technology (pp. 442-447). EEE. https://ieeexplore.ieee.org/abstract/document/576015 7

16. Sumithira, T. R., and A. Nirmal Kumar. "Elimination of harmonics n multilevel nverters connected to solar photovoltaic systems using ANFIS: an experimental case study." Journal of applied research and technology 11.1 (2013): 124-132.

http://www.scielo.org.mx/scielo.php?pid=S1665-

64232013000100011\&script=sci_arttext\&tlng=pthttp ://www.scielo.org.mx/scielo.php?pid=S1665-

$64232013000100011 \&$ script $=$ sci_arttext\&tlng $=\mathrm{pt}$

17. Das, S. S., Gupta, S. C., \& Rajkiran, U. (2014). Harmonic mitigation $\mathrm{n}$ wind energy conversion system by multilevel nverter. nternational Journal of Electrical, Electronics and Data Communication, 2(9).

18. Bhargava, N., Gupta, S., \& Phulambrikar, S. P. (2014). Analysis of asymetrical cascaded 7 level and 9 level multilevel nverter for design for asynchronous motor. nternational Journal of Engineering Research and Technology (IJERT), 3(8).

https://pdfs.semanticscholar.org/1d8c/f82fea27658f9 5d0b5baa5f24496473e8d89.pdf

19. Mahar, M. A., Uqaili, M. A., \& Larik, A. S. (2011). Harmonic analysis of ac-dc topologies and their mpacts on power systems. Mehran University Research Journal of Engineering \& Technology, 30(1), 173-178.

https://pdfs.semanticscholar.org/3415/9e0ee1619c0e9 041fb3496cdf8efc5426bcf.pdf

20. Stephen, P. M., Ponraj, M., Sathesh, N., Balamurugan, K., \& Karthikeyan, K. (2018). MODIFIED CASCADED H-BRIDGE MULTILEVEL NVERTER FOR HOUSEHOLD APPLIANCES. power, 5(03).

21. Derakhshanfar, M. (2010). Analysis of different topologies of multilevel nverters. Master of Science Thesis submitted to Department of Energy and Environment, CHALMERS UNIVERSITY OF TECHNOLOGY, Sweden

http://webfiles.portal.chalmers.se/et/MSc/Derakhshan farMSc.pdf

22. Prabaharan, N., \& Palanisamy, K. (2017). Analysis of cascaded H-bridge multilevel nverter configuration with double level circuit. IET Power Electronics, 10(9), 1023-1033.

https://digital-

library.theiet.org/content/journals/10.1049/ietpel.2016.0506

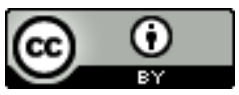

Journal of Applied and Emerging Sciences by BUITEMS is licensed under a Creative Commons Attribution 4.0 International License. 